\title{
Circus Art: An Aspect of Cross-Cultural Dialogue
}

\section{Svetlana Shumakova, Kharkov State Academy of Culture, Ukraine}

\begin{abstract}
The paper examines the problem of cross-cultural interactions; within this context circus art is analyzed. Art in general and especially circus art can be considered as a field of dialogical communication and as a way of giving new human experiences, spiritual values and worldviews. It is hypothesized that circus art is a complex polyfunctional social and cultural phenomenon, which inherits communicative properties of art. It is possible and desired to study circus art in the context of cross-cultural dialogue. The article deals with modern cultural situation and its orientation on cultural dialogism; it also displays general factors that form the role of circus art in the cross-cultural interaction.
\end{abstract}

Keywords: cultural situation; cross-cultural dialogue; circus art. 


\section{Introduction}

Circus art as a certain cultural phenomenon was investigated in the Ukrainian humanities, originated from the kindred Russian-language humanities, by V. A. Vladimirov (Vladimirov, 1987), A. Z. Zhytnytskyi (Zhytnytskyi, 1985) and S. M. Makarov (Makarov, 1974 ). ${ }^{1}$ Regretfully, there is no study devoted exclusively to the role of circus art in the cross-cultural dialogue yet. The paper aims to reveal and analyse the main factors forming the role of circus art in cross-cultural dialogue.

Culture develops itself by dialogueness, which is its fundamentally immutable property. The problem of cultural dialogue is considered to be very acute, since today's cultural situation with the domination of the global and the current development of cross-cultural communication systems broadens the horizons of cultural interactions between nations and peoples. By virtue of its importance and integrative functions in today's communicational processes, art is regarded as significant in cross-cultural dialogic interactions. Circus art stands out in the complex, open, multilevel communication system of art by taking us beyond the routine and opening up of new horizons of possibilities. It shrinks the distances between people, carrying live communication, which is essential in today's people's life, when live communication is being replaced by virtual communication that becomes more and more significant over time. Circus art uses the language of tricks, that is completely void of verbal characteristics, but at the same time being meaningful and expressive. The semiotic system of circus art has no limitations typical for natural language, and this fact widens the communicative possibilities of circus art. The trick language of circus art is not only understandable, but also has a high level of emotionality (especially in tricks related to risk for life and health of an artist, which increase viewers' empathy and eventually lead to the unity.)

Circus art is a complex polyfunctional cultural occurrence that displays the world view, world perception and mentality in performance cultural forms. This mentality manifests itself in the hierarchical system of people's ideas, views, estimations, tests, cultural canons and the ways of thought expressing. Thus, in speaking of circus art, we first of all mean by it a cultural phenomenon; therefore, its analysis is possible at the culture-logical level.

\footnotetext{
${ }^{1}$ The studies on the problem of "inclusion" in dialogic strategies should be also noticed, see in the References: M. Bakhtin , V. Bibler, M. Kagan, Yu. M. Lotman, A. Ya. Flier, N. Elias.
} 
Circus art influences the sphere of the formation of values and moral visions. In order to investigate the cultural potential of circus art and its function in cultural dialogism, I will first analyze the modern cultural situation and its orientation to dialogue.

\section{Cultural Situation}

Modern globalization and integrative social and cultural processes, caused by the communication revolution, originate the macro systemic transformation of the civilization. No culture is capable of functioning properly when being isolated from other cultures. Nowadays, a new tendency appears in culture: striving not only for conscious cultural creations, but also for the unification of created cultural and artistic meanings. Artistic communication transmits artistic texts, dialogic by their structure, so that the common ground could be found in dialogue.

Gradually, a new civilization paradigm is being formed, in which information comes on line in the light of high technology, and intellectual skills realization - in the light of creative activity. These circumstances give rise to the formation of the environment that creates the communication field of cultural dialogue tending to cultural integration. Consequently, today's globalization processes, which are of an integration character, refer to cross-cultural dialoguing. These processes differ from each other by their intensity at the level of complex systems (local cultures) as well as at the level of cultural areas (for instance, spiritual, artistic.) In relation to culturology, globalization, as judged by the ways of its manifestation, could be regarded as the display of cultural changeability. Cultural changeability evolves by three major vectors: cultural-genetic, transformational and de-semantical (Flier. 2002, 273.) Apart from the conditions listed above, there are also some intermediate conditions of cultural changeability that proceed in cultural space discordantly, asynchronously. Today's world cultural situation is characterized by its orientation towards coherence, which is the conformity of the behavior of the elements of general culture unified system. Coherence conditions the stability and harmony of multiculture development.

With the appearance of new technologies, the present information revolution forms the medium of information exchange with no geographic and political boarders. As a cultural form, the innovative link implemented in the context of everyday life, transfigures the whole social and cultural system (Flier, 1995, 17-19.) Due to the modern achievements of the 
scientific and technical progress, all the components of the unified multicultural world communicate with each other transgressing the boarders of local cultures. However, local cultures do not always complement each other during their interactions. They also enter into difficult, sometimes even conflicting relations. Besides, during the process of interactions every local culture reveals its specifics and distinctions; difficulties could arise due to the difference of expectations and prejudices which are often diverse in different cultures. This could lead to misunderstandings, tensions and potential conflicts. Therefore, cross-cultural interactions should be considered as the aggregate of various forms of relations and communication, aimed at the strengthening of mutual understanding and finding areas of common interests. These areas can transform the lack of cultural coordination between peoples into collaboration, interaction, and the adoption of cultural codes and experiences. The implementation of the experience of other cultures is desired to initiate dialogue concerning universal human values and worldviews. Dialogic interactions do not consist in the complete mergence and mixing of cultures, but in their mutual fertilization. In the complicated and ambiguous process of globalization, dialogic relations would facilitate to preserve the self-identity of particular cultures. The today's global informatization of social and cultural systems ensures their interaction: the acceptance of the developmental models of the West-European societies by the Eastern societies and vice versa. It was earlier maintained that cultures do not intersect each other in an essential extent, whereas today the ways of their interaction and mutual enrichment are accepted clearly and strongly.

The present informational revolution forms the civilizational development of culture. The genesis of culture could not be exhausted by the materialization of culture projects only. It also multiplies and preserves the world cultural heritage in the process of cross-cultural interactions.

Today's world culture is oriented to a new unknown stage, i.e. to the transition to new sources of the transmission and preservation of cultural experience. The representation of historical and cultural experience reveals cultural programs laid in the components of culture system. Culture always forms Lebenswelt and the consciousness of its bearers. Being a universal language of culture, art creates a basis of the dominant human emotional perception; on its level it facilitates changes of people's visions and values. The process of the adoption of cultural values is impossible without sensual perception, which is created by 
art. The universal human values penetrate into cultural dialogic interactions by means of art, creating the chance for every art form to delegate its best achievements into the universal human heritage. Art opens new depths of meanings via artistic values and is understandable for everybody.

In the context of art, the problem of authentic meanings transmission and transformation, every element of which influences the sociodynamics of the whole culture, manifests itself to the fullest extent in the performance forms of today's art. By virtue of its specifics, circus art takes a special place among them. The demand for this form of art is conditioned by its essential properties -the festive asserting of life and spectacularity, as it is intrinsic to human nature to need qualitatively new experiences, different from people's everyday life. Hereafter I will proceed to the investigation of the important cultural potential of circus art and its role in intercultural dialogue.

\section{Circus Art}

The spiritual capacity of circus art lies in its emotional potency for imaginative influence. Circus art is a unique symbiosis of specific knowledge and skills, the conglomerate of sacral and archaic symbols, signs, motives, approaches, ceremonials, which have transformed into a distinctive artistic world. This world became a traditional classical art asserting the universal moral, physical and spiritual values of humanity. Over thousands of years, the circus art accumulates and transfigures the cultural inheritance of the humanity imbibing carnival forms, folk and ethnographic features and traditions, i.e., the wide range of cultural symbolism. Thus, the art of circus is one of the most expressive elements of spiritual culture that contains the centuries-long experience of numerous generations, blazing trails of the cognition of the world. This art creates a special system of values and norms, a semiotic system grasped as a specific area of the knowledge and meanings of human life.

The circus, as the element of the open system of art, could be defined as a distinctive "house of mirrors among the mirrors," in which the form of mass introspection exists. The control and self-modification are possible due to this form at the society level and also at the personality level (Rushkoff, 2003, 5.) Circus art forms the field of possibility of the selfmodification of men, the alteration of their social qualities, behavioral stereotypes, changes and transforms the values and norms that actualize the personalities. The process of self- 
modification could be implemented by adopted ideas and culture forms. As a performance form, the art of circus contributes to the provision of the "social wrapping" of cultural forms. Circus art reflects the process of the development of human strengths and skills more than anything else, and, in a sense, also the characteristics of human development in general. This process finds its external embodiment in all the variety and diversity of the human reality creation, in all the totality of the results of human labor and thought.

At the background of thee worldwide status acquisition by culture, the circus art accumulates the best achievements of all the countries and peoples (not only in the artistic, intellectual or sport realms, but also in the science and engineering, which are particularly acute in the genre of illusion.) Synthetic by its nature, it reveals the links between the artistic polyphony form and classical arts, and it widens the artistic vision of a spectator by the vision of this arts.

Comparing circus art with other forms and genres of the general art system, one can state that being synthetic (containing the elements of expressiveness systems of other arts,) the circus art can adopt cultural meanings and carry on a dialogue most expressively and multifacetedly, as it represents almost all art forms. This is also intensified by the high emotionality level of the circus art language, which is an essential tool for uniting people and cultural values exchange. All the components in the structure of circus art, from thirty-meters wide circus ring and the spherical big top over the arena to the external form of tricks and requisites, "have a sign function” (Barinov, 2006, 96.) The symbolic meanings, encoded in acrobatic, juggler and illusion acts and transformations, show the underlying links of the spiritual and the physical. Circus art creates its imaginative "sense stereoscopy" and content-richness, fulfilling the process of the denoting and structuring of symbolic information (Barinov, 2006, 17.) Created artistic images symbolically express senses that are the essence of culture values and ideals.

The trick is the main unit of the language of this meaningful art. Tricks, as a language of any medium, reflect not only the emotional, but also the subconscious levels of information rendering. The artist that performs a trick renders signs, symbols and cultural codes, laid in this trick, to the spectator, as every trick has the conceptual kernel of its inherent meaning. The framing of a trick kernel with the context, created by expressive means (tempo-rhythm, color, light, sound, the specifics of equipment and requisite, visual effects etc,) carries 
interrelated characteristics of cultural senses which reflect the specifics of circus signs and symbols, to the spectator. Tricks form a high level of the interaction between the recipient and performer influencing emotionally the spectator. The communication, oriented towards cultural interactions, emerges while senses intersect as objects. The significance of these senses is estimated by the coefficient of the expressiveness of signs and code meanings. The sign interprets senses and is subject to the interpretation itself. The thinking of the spectator, who perceives the interpretative invariants of senses transmitted by tricks, bears the marks of creativity (Makarov, 1974, 47.)

The trick-sign, transforming in its meaning and intersecting with others, structurally changes. This conditions the orientation of circus art towards the integration of new senses and cognitive values. Circus art is oriented towards the creation of universal human values, included in the cultural context of the world, and towards universal unity in the process of cross-cultural dialogue interactions. The breakthrough to the "global" is not a subjective ambition but an essential destination of this art. Circus art, originated from the folk laugh tradition and play, reproducing a specific historical way of life of different people at all times, has been and still remains one of the most adequate ways of the artistic transmitting of information and the communication of culture. By means of circus art, every culture has an opportunity to be represented on the map of the integrated world culture.

The main goal of dialogue as a self-adjusting communication system is to obtain the understanding of its parties. Thus, circus art successfully acquires the ways for comprehension in cross-cultural dialogue, suggesting a conversation in its trick language. Circus art leaves its clear trace in the establishment of modern aspect of development of the universal world culture, determined by the modern cultural situation, which claims that there is no country or man in the modern world that can develop separately. The mutual dependencies between nations and people tend to increase constantly; separate cultures are able in a less degree of solving the key problems of great international significance (Sheiko, 2001, 469.)

At the level of its artistic projects transformation, circus art greatly contributes to the solving of today's problems, where the diversity of the humankind is a specific barrier on the way of the deepening of international cooperation and of the realization of global initiatives. The 
incredible closeness of circus art language to the psychological mechanisms of human perception helps to intensify the understanding and a further convergence of nations. Circus art successfully practices the principle of the unification of countries and peoples, despite the diversity of languages, ways of thinking and traditions of different ethnoses.

Making a cultural diffusion, circus art correlates the opening of cultural senses for contemporaries. This art reflects and grasps a concrete reality, thereby blazing its trail of the grasping of the internal sense of phenomena. Its reflection forms a basis for interactions of cultures, for their interpenetration and mutual enrichment. This is predefined by the structure, contents and the mechanism of circus art existence, adjusting dialogue on the equal base between irredundant to each other self-valued cultures. The cultures of different countries participate in international interaction via circus art in order to achieve a certain level of universal cultural integrity, revealing analogies and parallelism and allowing for the peculiarity of national mono-cultural systems. The dialogue, created by circus art, forms the harmonic unity of the multiplicity, which is most clearly reflected in numerous national and international circus festivals and competitions that provide the basis for comparison and better understanding of different cultures. Their popularity and significance confirms that among other forms and genres of art circus art represents people's cultures to each other quite multifacetedly, adequately and expressively; the distinguished culture of the East to the Western spectator, and the Western one- to the Eastern spectator. Foreign traditions and values become more available and understandable. Circus art as a complex social and cultural phenomenon creates a dialogue at the intersection of senses, laid in its language, and thus multicultural interaction occurs, grasping the richness of the sign and symbolic world of culture.

\section{Conclusions}

The role of circus art in worldwide culture is presented in the following theses:

1. The language of circus art, which carries "live" communication and is oriented towards unity, has no limitations typical for natural languages. This conditions its applicability in cross-cultural interactions.

2. Circus art is not only a technique of cultural comparison, differentiation and unification, but also a tool for the transformational cognition and correction of cultural and personal holistic value systems. 
3. All the elements of the complex and open structure of circus art eventually strive to reveal the links between cultural cognition and the system of universal human values.

4. The incredible closeness between the meaning of trick and the stereotypes, psychological mechanisms of human perception does not depend on ethnographic factors. That results in the permanent topicality of circus art in dialogue.

5. By virtue of its synthetical character, circus art represents the cultures of different countries and peoples to each other, including those ones of the West and the East, in a very multifaceted, adequate and expressive way.

6. The life-asserting strategy and commonness of the goals at the international level, represented by circus art, are the factors of cross-cultural interaction establishment and unification. 


\section{References}

Barinov, V. 2006. Trick in circus. Moscow: Redegir.

Bakhtin, M. 1989. Verbal Creativity Aesthetics. Moscow: Iskusstvo.

Bibler, V. 1989. “Culture. Dialogue of Cultures. Identification Experience.” Philosophical Issues, 6, 42-49.

Burlaka, V. 2005. "Reality Checking_Postmedium Realism in the Creative Work of Modern Ukrainian Artists.” Modern Art, 2, 20-30.

Elias, N. 1991. Society of Individuals. Oxford: Blackwell.

Flier, A. 2002. Culturology for Culturologists. Moscow: Delovaya Kniga.

Kagan, M. 2003. Introduction to the History of World Culture. Saint-Petersburg: Petropolis.

Lotman, Y. 1992. Articles Semiotics and Cultural Topology. Tallinn: Alexander.

Makarov, S. 1974. Folk Traditions of Clowning. Author's Abstract of the Thesis of Candidate in History of Art: Moscow.

Rushkoff, D. 2003. Media Virus: How Pop Culture Secretly Influences Your Conscience. Moscow: Interkniga.

Sheiko, V., Yu. Bohutskyi. 2005. Formation of Culturology Fundamentals in the Epoch of Civilizational Globalization. Kyiv: Heneza.

Sheiko, V. 2001. Culture. Civilization. Globalization (End of 19th-Beginning of the 21th Century). Kharkov: Osnova.

Vladimirov, V. 1987. Circus as the Phenomenon of Culture. Thesis of the Candidate of Philosophical Sciences. Moscow: M. V. Lomonosov Moscow State University. Zhytnytskyi, A. 1985. Topical Problems of Circus Dramaturgy Theory: Dramaturgy of Carpet Clowning-Genesis, Evolution, Typology, Composition Approaches and Modern State. Thesis of the Candidate in History of Art. Moscow. 